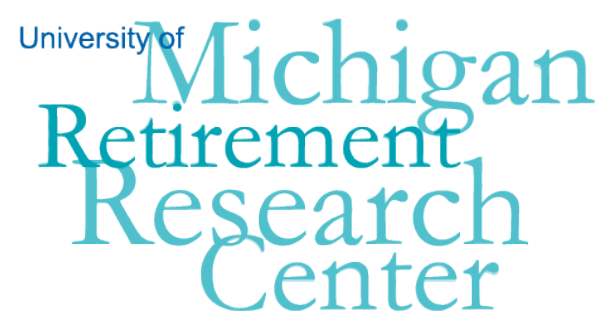

Working Paper

WP 2013-289

\title{
Disability Insurance and Healthcare Reform: Evidence from Massachusetts
}

\author{
Nicole Maestas, Kathleen J. Mullen, and Alexander Strand
}

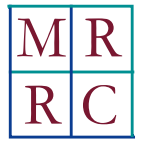

Project \#: UM12-17 



\title{
Disability Insurance and Healthcare Reform: Evidence from Massachusetts
}

\author{
Nicole Maestas \\ RAND \\ Kathleen J. Mullen \\ RAND \\ Alexander Strand \\ Social Security Administration \\ November 2013 \\ Michigan Retirement Research Center \\ University of Michigan \\ P.O. Box 1248 \\ Ann Arbor, MI 48104 \\ http://www.mrrc.isr.umich.edu \\ (734) 615-0422
}

\section{Acknowledgements}

This work was supported by a grant from the Social Security Administration through the Michigan Retirement Research Center (Grant \# 5 RRC08098401-04-00). The findings and conclusions expressed are solely those of the author and do not represent the views of the Social Security Administration, any agency of the Federal government, or the Michigan Retirement Research Center.

\section{Regents of the University of Michigan}

Mark J. Bernstein, Ann Arbor; Julia Donovan Darlow, Ann Arbor; Laurence B. Deitch, Bloomfield Hills; Shauna Ryder Diggs, Grosse Pointe; Denise Ilitch, Bingham Farms; Andrea Fischer Newman, Ann Arbor; Andrew C. Richner, Grosse Pointe Park ; Katherine E. White, Ann Arbor; Mary Sue Coleman, ex officio 


\title{
Disability Insurance and Healthcare Reform: Evidence from Massachusetts
}

\begin{abstract}
As health insurance becomes available outside of the employment relationship as a result of the Affordable Care Act (ACA), the cost of applying for Social Security Disability Insurance (SSDI) — potentially going without health insurance coverage during a waiting period totaling 29 months from disability onset - will decline for many people with employer-sponsored health insurance. At the same time, the value of SSDI and Supplemental Security Income (SSI) participation will decline for individuals who otherwise lacked access to health insurance. We study the 2006 Massachusetts healthcare reform to estimate the potential effects of the ACA on SSDI and SSI applications.
\end{abstract}

\section{Citation}

Maestas, Nicole, Kathleen J. Mullen, and Alexander Strand (2013). "Disability Insurance and Healthcare Reform: Evidence from Massachusetts.” Ann Arbor MI: University of Michigan Retirement Research Center (MRRC) Working Paper, WP 2013-289. http://www.mrrc.isr.umich.edu/publications/papers/pdf/wp289.pdf

\section{Authors' Acknowledgements}

Maestas: RAND Corporation, 1776 Main Street, Santa Monica, CA 90401 (e-mail: maestas@rand.org); Mullen: RAND Corporation, 1776 Main Street, Santa Monica, CA 90401 (e-mail: kmullen@rand.org); Strand: Social Security Administration, 500 E Street, 9th Floor, Washington, DC 20254 (e-mail: Alexander.Strand@ssa.gov). We thank Mary Daly, David Grembowski, Jonathon Kolstad, Adam Shapiro and seminar participants at the Leonard Davis Institute of Health Economics at the University of Pennsylvania and University of Washington School of Public Health for helpful comments and suggestions. This research was supported by a grant from the U.S. Social Security Administration (SSA) through the Michigan Retirement Research Center (MRRC). The opinions and conclusions expressed are solely those of the authors and do not represent the opinions or policy of SSA or any agency of the Federal Government. 


\section{Introduction}

The unfolding reforms to the U.S. healthcare system laid out by the Affordable Care Act (ACA) in 2010 will fundamentally alter the costs and benefits of applying for federal disability benefits through the Social Security Disability Insurance (SSDI) and Supplemental Security Income (SSI) programs. SSDI recipients are entitled to health insurance coverage through the Medicare program, but only after they satisfy a two-year waiting period that begins with the date they qualify for benefits. ${ }^{1}$ SSI recipients are entitled to Medicaid coverage immediately upon qualifying for benefits. Applicants to both programs may face substantial uncertainty about whether their disabilities qualify for benefits and how long they may have to wait for a disability determination.

Because at present most non-elderly adults in the United States obtain health insurance coverage through their employer, individuals who experience the onset of a work-limiting health condition face a difficult dilemma: attempt to keep working in spite of an uncomfortable impairment in order to maintain employer-sponsored health insurance (ESHI) or stop working in order to apply for SSDI or SSI and risk an extended period of uninsurance. Some of these individuals may be able to obtain subsidized coverage through a spouse’s employer. Others may be able to retain their employer coverage temporarily under COBRA provisions, but at full cost during a period without labor earnings. ${ }^{2}$ If the disincentive arising from loss of health insurance coverage presently discourages labor force withdrawal and disability benefit application, then the ACA's introduction of affordable health insurance coverage outside of employment could free workers from “employment lock,” and consequently increase both disability-related labor force withdrawal and disability applications.

\footnotetext{
${ }^{1}$ The 24-month Medicare waiting period begins after the 5-month waiting period for entitlement to cash benefits. ${ }^{2}$ COBRA provisions allow for an extended time limit (from 18 months to 29 months) in the event the former employee receives a disability determination from SSA within the first 60 days of continuation coverage.
} 
On the other hand, the introduction of affordable coverage options outside of SSDI and SSI could reduce the relative value of disability benefits for those who didn't have ESHI or were uninsured at the time of disability onset, and hence could decrease federal disability applications. Indeed, health insurance benefits are more valuable than cash benefits for many beneficiaries (Mashaw, 1997). Which of these two countervailing effects is likely to dominate the other is an important empirical question.

The recent implementation of healthcare reform in the state of Massachusetts (MA) offers a unique opportunity to forecast the impact of the ACA on SSDI and SSI applications. The MA reform shares many key features with the ACA reform, most notably, a new individual coverage mandate, an expansion of subsidized coverage for low-income individuals, the creation of an insurance exchange as a source of lower-cost individual coverage, and new requirements for employers. The MA reform legislation was passed in April 2006 and phased in primarily between October 2006 and July 2007. The reform was associated with an increase in the rate of insurance coverage among the nonelderly in MA from 88 percent in 2004-2006 to 94 percent in 2008-2009, an increase of 6 percent or, alternatively, a decrease in the uninsurance rate of 48 percent (Kolstad and Kowalski, 2012). The ACA is expected to increase insurance coverage by a similar magnitude (Truffer et al., 2010).

In this paper we use administrative data from the Social Security Administration (SSA) to examine changes in SSDI and SSI application rates in MA before and after the reform relative to a group of comparison states that are similar in size, demographic composition and geographic location. We find that disability applications increased modestly in MA relative to neighboring states in the first year following the completion of the reform with no statistically significant difference thereafter. However, this result masks substantial heterogeneity at the county level: total 
SSDI and SSI applications increased in counties that had high levels of health insurance prior to the reform and decreased in counties with low levels, although applications for SSDI only (i.e., excluding "concurrent” applications for both SSDI and SSI) increased everywhere. Because health insurance coverage in the rest of the U.S. is generally lower than the level in MA prior to the 2006 reform, our results imply that the ACA may lead to a net decrease in DI applications in the U.S., with some shift, at least initially, in the composition of new applications to SSDI.

\section{The Health Insurance Landscape for Individuals with Work-Limiting Health Problems in Massachusetts before and after the Reform}

Prior to the enactment of its health reform law in 2006, MA had a relatively generous system of public health insurance compared to other states and a relatively low uninsurance rate. In addition to the mandatory Medicaid programs that all states were required to offer, MA offered most of the optional Medicaid programs and under a Medicaid demonstration waiver tended to use relatively generous income and asset thresholds for determining eligibility for these programs. ${ }^{3} \mathrm{MA}$ residents who were long-term unemployed or who were certified disabled ${ }^{4}$ could enroll in fully subsidized "poverty-level” Medicaid coverage if their incomes were below 133\% of the Federal Poverty Guideline (FPG). In theory, the long-term unemployed program was an option for people whose disabilities did not meet SSA's strict severity standard, but who had been unable to work for at least a year. However, enrollment in the two programs was capped and there was a long waiting list (itself equal to $29 \%$ of the cap) for the unemployed program (MassEssential) at the time the

\footnotetext{
${ }^{3}$ See Bruen, Wiener and Thomas (2003) for a description of state mandatory and optional Medicaid programs for disabled beneficiaries prior to the MA health reform.

${ }^{4}$ MA uses the SSA standard for defining disability. To be considered disabled for the purpose of qualifying for MassHealth, individuals must provide evidence of a disability determination from SSA or the state Disability Determination Unit, or a certification of legal blindness from the MA Commission for the Blind.
} 
reform was implemented (Blue Cross MA Foundation, 2006). MA residents who were "working disabled" (those with certified disabilities who were working at least 40 hours per month) and had incomes above 133\% FPG could pay an income-adjusted premium for Medicaid coverage through the state’s Medicaid Buy-In program (CommonHealth Working). ${ }^{5}$ On the eve of reform in 2006, the MA Medicaid Buy-In program was the largest such program in the country, but even at that time the program enrolled only about $5 \%$ of the working-age disabled (60\% of whom were already SSDI/SSI beneficiaries) (Gimm et al., 2008). Thus, even under this relatively generous public coverage landscape, people whose disabilities did not necessarily meet SSA's strict severity standard lacked an option for affordable coverage-whether working (because they didn't meet the disability criteria for the Medicaid Buy-In program) or not working (due to the binding cap on the program for the long-term unemployed with incomes below 133\% FPG and the lack of a subsidized option for people with incomes above 133\% FPG).

It was in this context that the MA legislature passed the health insurance reform in April 2006. The reform was implemented in several steps. The first step was the raising of the enrollment cap on Medicaid coverage for the long-term unemployed with incomes below $100 \%$ of FPG in October 2006. Subsidized insurance plans for lower-income individuals (up to 300\% of FPG) were made available through Commonwealth Care by January 2007. In May 2007 open enrollment began for Commonwealth Choice, which enabled individuals who were not eligible for Commonwealth Care to purchase insurance offered by private health plans through a newly created health insurance exchange called the Health Connector. An individual mandate - which required most Massachusetts adults to carry health insurance - and employer mandate - which required employers with more than 10 full-time equivalent employees to offer health insurance or face a penalty - went into effect

\footnotetext{
${ }^{5}$ The program was generous compared to other Medicaid state Buy-In programs in that it had no upper limit on income or assets.
} 
in July 2007. By the end of 2007 Massachusetts adults were required to show they were enrolled in a health insurance plan on their state taxes, with penalties increasing in 2008. By January 1, 2009 the reform was fully phased in.

The effect of the MA reform on the options available to the disabled varied for different groups. For example, the MA reform did not change much for people whose disability clearly met SSA's strict severity standard. For this group, the reform maintained fully subsidized poverty-level Medicaid coverage up to 133\% FPG, the one-time deductible for people with income between 133150\% FPG, and income-adjusted premiums above 150\% FPG (essentially dropping the distinction between working and non-working in the Buy-In program). However, for those whose disabilities did not clearly meet SSA's strict severity standard (i.e., those who were "moderately disabled"), it created new subsidized insurance options. It raised the enrollment cap on the long-term unemployed program by $36 \%$ (enough to fully absorb the waiting list), and created fully subsidized private insurance options (independent of employment or disability status) for people with income below 150\% and partially subsidized private insurance options for people between 150-300\% FPG—all available through the new state insurance exchange. It also created more affordable, but unsubsidized private insurance plans through the exchange.

Before the MA reform, people with work-limiting health problems either had access to affordable health insurance through a job (their own or spouse's) or through a formal disability determination. By creating a path to public health insurance coverage that did not require access to ESHI or a favorable disability determination, individuals could now leave their jobs and still obtain health insurance during the two-year waiting period and potentially beyond, regardless of the outcome of the disability determination process. This easing of "employment lock" could have induced an increase in applications from people on the margin of SSDI eligibility with incomes 
between 150-300\% FPG (who gained access to subsidized coverage) and also from people on the margin of eligibility with incomes above 300\% FPG (who gained access to more affordable (unsubsidized) private coverage through the exchange). Conversely, by creating new options for health insurance, the MA reform decreased the relative value of SSDI and SSI and may have discouraged applications from people without access to affordable health insurance coverage prior to the reform, including the long-term unemployed and workers without ESHI.

\section{Data and Empirical Strategy}

Our primary data source is the Social Security Administration's 831 files which contain the universe of all SSDI and SSI applications. These data contain the application filing date, whether the applicant filed for SSDI or SSI benefits or both (concurrent), and other application characteristics. Importantly, it includes the applicant's zip code, which enables us to identify county of residence for the vast majority of applicants. We match zip codes to counties probabilistically using the Census Bureau’s definitions of zip code tabulation areas (ZCTAs) and a geographic correspondence engine made available by the Missouri Census Data Center. ${ }^{6}$ Although most ZCTA codes in our sample correspond to only one county, in cases where the ZTCA corresponds to more than one county we allocate partial applications to the corresponding counties using weights based on the fraction of residents in the ZCTA residing in each county at the time of the 2010 Census. $^{7}$ We aggregate applications by county and quarter of filing. Our main dependent variable is number of initial applications filed in a quarter per 1,000 working age (ages 20-59) residents, where the

\footnotetext{
${ }_{7}^{6}$ http://mcdc1.missouri.edu/MableGeocorr/geocorr2010.html

${ }^{7}$ A very small portion of ZCTAs are not matched to any county by the correspondence engine ( $2 \%$ of applications in our data). These are approximately divided equally into unusable codes (“00000" or "99999") and potentially usable codes for which our correspondence engine is likely out of date.
} 
denominator is taken from Census population estimates. We drop counties with fewer than five applications filed in any quarter during the sample period.

We restrict our sample to applications filed by disabled workers ages 18-64 between October 2004 and September 2008 in MA and the other states in the Northeast Census division excluding Rhode Island, which has a large fraction of missing zip codes at various points in the observation period. ${ }^{8,9}$ These states were chosen because they were geographically close to MA and also similar in terms of observable characteristics such as population size, income, race, education (not shown) and, importantly, unemployment rates and DI application rates, which were falling in both MA and the Northeast prior to the reform (see Table 1).

We estimate the effect of the MA reform on SSDI/SSI applications and other outcomes using a difference-in-differences research design where we examine changes in SSDI/SSI rates in MA after the reform relative to changes in the comparison states. This approach allows us to control for any structural shifts in the post-period assuming they are the same in the treatment (MA) and comparison states. The following equation represents our main difference-in-differences specification:

$$
y_{c t}=\sum_{j=1}^{3}\left[\beta_{j}\left(M A_{c} * \operatorname{Post}_{t} * Y_{j}\right)+\gamma_{j} \text { Post }_{t}^{*} Y_{j}\right]+\delta U E_{c t}+\alpha_{t}+\mu_{c}+\varepsilon_{c t} \text {, }
$$

where $y_{c t}$ measures an outcome of interest (e.g., the rate of DI applications per 1,000 working age residents) in county (or state) $c$ in quarter $t, M A_{c}$ is an indicator for whether the county is in Massachusetts, Post $_{t}$ is an indicator for whether quarter $t$ occurs in the post-reform period

\footnotetext{
${ }^{8}$ Starting in 2009, the incidence of missing zip codes increases dramatically in MA as well as CT, RI and VT. This was due to a glitch in the software program that managed the electronic records that affected 30 states/territories.

${ }^{9}$ Maine and Vermont also implemented health reforms in 2003 and 2006, respectively. All three reforms created new coverage options and expanded public coverage, although only Massachusetts implemented a mandate. See Kaye and Snyder (2007) for more details. The results are robust to exclusion of ME and VT in the control group.
} 
(beginning in $2006 \mathrm{Q} 4$ ) and $Y_{j}$ is an indicator for the year of the post-reform period. The specification includes controls for the local unemployment rate $\left(U E_{c t}\right)$, indicators for quarter-year $\left(\alpha_{t}\right)$ to flexibly control for common factors such as macroeconomic conditions that influence disability applications and/or enrollments in each quarter. Similarly, $\mu_{c}$ is a county effect that controls for fixed, county-specific components of application flows. We cluster standard errors at the state level. The coefficients of interest are $\beta_{j}$, which measures the increase in applications in year $j$ after the reform for MA relative to the other states.

We examine heterogeneity in the impact of the MA reform in two ways. First, we separately examine changes in SSDI and SSI applications. The types of individuals eligible for SSDI only and SSI (including concurrent applications) differ in important ways. To apply for SSDI, individuals must have accumulated sufficient and recent work history. To apply for SSI individuals must have sufficiently low income and assets. Concurrent eligibles, with sufficient recent work history but very low income and assets, likely have a higher proportion who are long-term unemployed. Additionally, SSDI and SSI offer different types of insurance coverage (Medicare vs. Medicaid) at different times (after a two-year waiting period vs. immediately upon benefit entitlement). These features alter the balance of costs and benefits associated with disability application, and so it is reasonable to expect that the MA reform might affect the different programs in different ways. As described above, we might expect applications for SSDI only to increase and applications for SSI to decrease.

Second, we examine heterogeneity at the county level, by estimating the effect of the reform separately for counties with low vs. high levels of pre-reform (2005) insurance coverage, defined as below and above $88 \%$ (dividing the working age population in MA approximately in half). Since increased access to Medicaid may have discouraged SSI applications from previously uninsured 
individuals, we expect any decreases in those types to be concentrated in low insurance counties. Similarly, easing of "employment lock" may encourage SSDI applications from individuals previously covered by ESHI, so we expect increases in SSDI applications to come from high insurance counties.

\section{Results and Discussion}

Prior to health insurance reform in Massachusetts, during the economic expansion, application rates for SSDI and SSI had been declining in the Northeastern states, including Massachusetts (see Panel A of Table 1). However, after the reform was implemented in fiscal year 2007, Massachusetts experienced a modest increase in applications that was not experienced in the comparison states. By fiscal year 2009, the effects of the recession led to sharp increases in applications in all the states in the Northeast.

Table 2 estimates changes in applications for fiscal years 2007, 2008 and 2009 while controlling for common shocks and differences in unemployment rates in the difference-indifferences framework. We have ambiguous expectations for fiscal year 2007 because the reforms had not yet been fully implemented. We estimate an increase in applications for fiscal year 2008 in Massachusetts relative to the rest of the Northeast that disappears by fiscal year 2009. This suggests that health insurance reform may have led to a momentary increase in applications, possibly due to "pent-up demand" for disability benefits among those who had been working with impairments - a narrative compatible with a reduction in employment lock. At the same time, the dramatic increase in unemployment rates in all states around that time may also have dampened the effects of the reform on disability applications. The increase in applications is driven primarily by increases in applications for DI only, excluding concurrent applications. 
Switching to county-level analysis allows us to decompose the effect in Massachusetts into effects in low and high health insurance counties. While the high insurance county estimates mirror the overall estimates, the low insurance counties actually experienced a net decrease in SSDI and SSI applications relative to neighboring counties in fiscal year 2008. (Recall that, due to data limitations, we cannot conduct county-level analyses past fiscal year 2008.) This is also true in fiscal year 2007, perhaps due to the fact that the Medicaid expansions occurred early in the implementation period, compared with the opening of the exchange. This net decrease occurred despite the fact that, contrary to our expectations, SSDI-only applications increased even in the low insurance counties.

One potential explanation is that individual incentives do not explain the whole story. For example, one way for states to offset the financial burden of increasing public health insurance coverage is to encourage qualifying individuals to apply for federal disability programs. If this is the case, then we might expect to see an increase in applications from those who have been living with their impairments for a long period of time. ${ }^{10}$ On the other hand, if employment lock is the main driver of new applications, then we would expect to see a decrease in applications from those who had been disabled a long time before filing. In Table 4, we estimate the impact of the reform on the average time between onset of impairments (as defined by SSA) and filing for benefits in low and high-insurance counties. While SSDI-only applicants in low-insurance counties were disabled on average 0.5-1 months longer before filing after the reform vs. before the reform, SSDIonly applicants in high insurance counties were disabled 1-2 months less before filing after vs.

\footnotetext{
${ }^{10}$ Individuals with congenital conditions or the long-term unemployed would have relatively long delays, compared to newly unemployed individuals, due to SSA's definition of onset as the intersection of poor health and earnings falling below the threshold for substantial gainful activity (\$1,010 per month in 2010). We only observe onset for individuals who were allowed into the program at the initial level (approx. one-third of applications).
} 
before the reform. This is consistent with both individual and state-level incentives leading to (momentary) increases in SSDI applications.

Finally, viewing the MA reform as a test case for the ACA, because health insurance coverage is lower in the U.S. (84\% in 2010) than in MA prior to its reform, our estimates point to a likely decrease in the overall SSDI and SSI caseload relative to current trends, with some shift, at least initially, in the composition of new applications toward SSDI compared with SSI. 


\section{References}

Blue Cross Foundation of Massachusetts (2006). Massachusetts Health Care Reform Bill Summary. Accessed on 9/28/2012 at http://bluecrossmafoundation.org/foundationroot/en_US/documents/MassHCReformLawSummary.pdf

Bruen, B.K., J.M. Wiener and S. Thomas, 2003. “Medicaid Eligibility Policy for Aged, Blind, and Disabled Beneficiaries.” Washington, D.C.: AARP, Public Policy Institute.

Gimm, Gilbert, Sarah R. Davis, Kristin L. Andrews, Henry T. Ireys and Su Liu, 2008. “The Three E’s: Enrollment, Employment, and Earnings in the Medicaid Buy-In Program, 2006.” Mathematica Policy Research Report, Reference No. 6170-330.

Kaye, Neva and Andrew Snyder, 2007. "Health Reform in Maine, Massachusetts and Vermont: An examination of state strategies to improve access to affordable, quality care.” Maine Health Access Foundation Issue Brief, March 2007, Accessed on 10/30/12 at http://www.nashp.org/sites/default/files/Health_Reform_Brief_MHAF.pdf.

Kolstad, Jonathan T. and Amanda E. Kowalski, 2012. "The Impact of Health Care Reform on Hospital and Preventive Care: Evidence from Massachusetts.” Journal of Public Economics, 96, 909-929.

Mashaw, J.L., 1997. "Findings of the Disability Policy Panel,” in V.P. Reno, J.L. Mashaw and B. Gradison, eds. Disability: Challenges for Social Insurance, Health Care Financing and Labor Market Policy. Washington, D.C.: National Academy of Social Insurance.

Truffer, Christopher J., Sean Keehan, Sheila Smith, Jonathan Cylus, Andrea Sisko, John A. Poisal, Joseph Lizonita, and M. Kent Clemens. 2010. "Health Spending Projections through 2019: The Recession’s Impact Continues,” Health Affairs, 29(3), 522. 
TABLE 1 - DESCRIPTIVE STATISTICS

\begin{tabular}{|c|c|c|}
\hline & Massachusetts & Other Northeast states \\
\hline \multicolumn{3}{|c|}{ Panel A. All applications (rate per 1,000 working age residents, per quarter) } \\
\hline FY 2003 & 2.69 & 2.72 \\
\hline FY 2004 & 2.74 & 2.78 \\
\hline FY 2005 & 2.67 & 2.62 \\
\hline FY 2006 & 2.60 & 2.63 \\
\hline FY 2007 & 2.58 & 2.56 \\
\hline FY 2008 & 2.62 & 2.56 \\
\hline FY 2009 & 2.88 & 2.89 \\
\hline \multicolumn{3}{|c|}{ Panel B. SSDI total (rate per 1,000 working age residents, per quarter) } \\
\hline FY 2003 & 2.03 & 1.97 \\
\hline FY 2004 & 2.10 & 2.06 \\
\hline FY 2005 & 2.04 & 1.93 \\
\hline FY 2006 & 1.97 & 1.93 \\
\hline FY 2007 & 1.95 & 1.86 \\
\hline FY 2008 & 1.98 & 1.85 \\
\hline FY 2009 & 2.17 & 2.09 \\
\hline \multicolumn{3}{|c|}{ Panel C. SSI total (rate per 1,000 working age residents, per quarter) } \\
\hline FY 2003 & 1.76 & 1.66 \\
\hline FY 2004 & 1.82 & 1.71 \\
\hline FY 2005 & 1.77 & 1.61 \\
\hline FY 2006 & 1.74 & 1.65 \\
\hline FY 2007 & 1.73 & 1.62 \\
\hline FY 2008 & 1.75 & 1.64 \\
\hline FY 2009 & 1.92 & 1.84 \\
\hline \multicolumn{3}{|c|}{ Panel D. DI only (rate per 1,000 working age residents, per quarter) } \\
\hline FY 2003 & 0.94 & 1.07 \\
\hline FY 2004 & 0.93 & 1.07 \\
\hline FY 2005 & 0.90 & 1.01 \\
\hline FY 2006 & 0.86 & 0.98 \\
\hline FY 2007 & 0.85 & 0.94 \\
\hline FY 2008 & 0.86 & 0.92 \\
\hline FY 2009 & 0.97 & 1.05 \\
\hline \multicolumn{3}{|c|}{ Panel E. Unemployment rate } \\
\hline FY 2005 & 4.85 & 4.88 \\
\hline FY 2006 & 4.81 & 4.70 \\
\hline FY 2007 & 4.54 & 4.37 \\
\hline FY 2008 & 4.88 & 5.00 \\
\hline FY 2009 & 7.58 & 7.68 \\
\hline \multicolumn{3}{|c|}{ Panel F. Uninsurance rate } \\
\hline CY 2005 & 8.6 & 11.3 \\
\hline CY 2010 & 5.5 & 13.4 \\
\hline
\end{tabular}

Source: Authors’ calculations for panels A-D; Bureau of Labor Statistics for panel E; Census Bureau Health Insurance Historical Tables for panel F. Means in non-MA states weighted by working age population taken from Census. 
TABLE 2. STATE-LEVEL ESTIMATES OF EFFECT OF MA HEALTHCARE REFORM ON DISABILITY APPLICATIONS

\begin{tabular}{lcccc}
\hline \hline & All applications & SSDI total & SSI total & DI only \\
\hline MA_FY2007 & $0.0407^{*}$ & 0.0295 & 0.0113 & $0.0295^{*}$ \\
& $(0.0198)$ & $(0.0247)$ & $(0.0254)$ & $(0.0134)$ \\
MA_FY2008 & $0.0800^{* * *}$ & $0.0703^{* *}$ & 0.0153 & $0.0647^{* * *}$ \\
& $(0.0152)$ & $(0.0264)$ & $(0.0189)$ & $(0.0170)$ \\
MA_FY2009 & 0.0148 & 0.0234 & -0.0257 & 0.0405 \\
& $(0.0560)$ & $(0.0272)$ & $(0.0374)$ & $(0.0325)$ \\
NT & 279 & 279 & 279 & 279 \\
N & 9 & 9 & 9 & 9 \\
R-squared & 0.962 & 0.960 & 0.958 & 0.917 \\
\hline
\end{tabular}

All regressions are weighted by working age population and include state and quarter-year fixed effects. Observation period extended to 2002q1-2009q3 and includes Rhode Island. Standard errors in parentheses clustered at state level. ${ }^{* * *} \mathrm{p}<0.01,{ }^{* *} \mathrm{p}<0.05,{ }^{*} \mathrm{p}<0.1$. 
TABLE 3-COUNTY-LEVEL ESTIMATES OF EFFECT OF MASSACHUSETTS HEALTHCARE REFORM ON DisABILITY APPLICATIONS

\begin{tabular}{lcccc} 
& All application & SSDI total & SSI total & SSDI only \\
\hline Panel A. All Counties & & & & \\
MA_FY 2007 & -0.00724 & -0.00496 & -0.0107 & 0.00347 \\
& $(0.0121)$ & $(0.0184)$ & $(0.0133)$ & $(0.0068)$ \\
MA_FY 2008 & $0.0340^{*}$ & 0.0483 & -0.0129 & $0.0469 * * *$ \\
& $(0.0161)$ & $(0.0285)$ & $(0.0164)$ & $(0.0085)$ \\
\hline Panel B. Low Insurance Counties & & & \\
MA_FY 2007 & $-0.0617^{* * *}$ & $-0.0470^{* * *}$ & $-0.0665^{* * *}$ & 0.00482 \\
& $(0.0048)$ & $(0.0084)$ & $(0.0121)$ & $(0.0111)$ \\
MA_FY 2008 & $-0.0610^{* * *}$ & $-0.0266^{* *}$ & $-0.106 * * *$ & $0.0448^{* * *}$ \\
& $(0.0090)$ & $(0.0080)$ & $(0.0073)$ & $(0.0108)$ \\
\hline Panel C. High Insurance Counties & & & \\
MA_FY 2007 & 0.0405 & 0.0372 & 0.0327 & 0.00782 \\
& $(0.0361)$ & $(0.0351)$ & $(0.03)$ & $(0.0082)$ \\
MA_FY 2008 & $0.133^{* *}$ & $0.137 * *$ & $0.0794^{*}$ & $0.0540^{* * *}$ \\
& $(0.0393)$ & $(0.0458)$ & $(0.0396)$ & $(0.0134)$ \\
\hline
\end{tabular}

Notes: All regressions weighted by working age population and include county and quarter-year fixed effects. Robust standard errors in parentheses clustered at state level. Low insurance counties defined by 2005 health insurance coverage rate < 88\%. "All applications includes SSDI only, SSI only and concurrent applications. "SSDI total" includes SSDI only and concurrent applications. "SSI total" includes SSI and concurrent applications.

*** Significant at the 1 percent level.

** Significant at the 5 percent level.

* Significant at the 10 percent level. 
TABLE 4-EFFECT OF MASSACHUSETTS HEALTHCARE REFORM ON TIME TO FILING

\begin{tabular}{|c|c|c|}
\hline & SSDI only & SSI total \\
\hline \multicolumn{3}{|c|}{ Panel A. Low Insurance Counties } \\
\hline \multirow[t]{2}{*}{ MA_FY 2007} & $1.099 * * *$ & $3.464 * * *$ \\
\hline & $(0.267)$ & $(0.945)$ \\
\hline \multirow[t]{2}{*}{ MA_FY 2008} & $0.511^{* * *}$ & $8.531^{* * *}$ \\
\hline & $(0.134)$ & $(1.543)$ \\
\hline \multicolumn{3}{|c|}{ Panel B. High Insurance Counties } \\
\hline \multirow[t]{2}{*}{ MA_FY 2007} & $-1.438 * * *$ & $3.733^{* * *}$ \\
\hline & $(0.318)$ & $(0.254)$ \\
\hline \multirow[t]{2}{*}{ MA_FY 2008} & $-2.098 * *$ & $6.697 * * *$ \\
\hline & $(0.586)$ & $(0.487)$ \\
\hline
\end{tabular}

Notes: All regressions weighted by working age population and include county and quarter-year fixed effects. Robust standard errors in parentheses clustered at state level. Mean time in months from SSA-defined onset to filing conditional on initial allowance in MA prior to reform: 14.1 SSDI only, 2.6 concurrent, 1.4 SSI only. Low insurance counties defined by 2005 health insurance coverage rate $<88 \%$.

$* * * \mathrm{p}<0.01, * * \mathrm{p}<0.05, * \mathrm{p}<0.1$. 